\title{
A aprendizagem através de experimentos no Ensino de Física
}

Learning through Experiments in Teaching Physics

\author{
R. N. S. Gonçalves ${ }^{1 *}$; J. E. de Andrade ${ }^{1}$; R. A. P. Oliveira ${ }^{2}$ \\ 1 Faculdade de Engenharia Mecânica/Instituto de Geociências e Engenharias, \\ Universidade Federal do Sul e Sudeste do Pará, CEP 68.505-080, Marabá-PA, \\ Brasil \\ 2 Colegiado de Engenharia Elétrica, Universidade Federal do Vale do São \\ Francisco, CEP 48.902-300, Juazeiro-BA, Brasil \\ *robertonsg@unifesspa.edu.br
}

(Recebido em 31 de agosto de 2016; aceito em 11 de dezembro de 2016)

\begin{abstract}
A experimentação é sem dúvida um dos grandes pilares da Física e uma importante forma de fomentar o processo de ensino-aprendizagem contextualizado e dinâmico. Entretanto, a experimentação por si só, sem uma reflexão profunda do fenômeno, sem dar a oportunidade do discente questioná-lo e construir a visão dos fenômenos da natureza pode ser uma pseudo-aprendizagem. Neste trabalho pontuaremos sobre as motivações, as condições e possíveis contribuições da experimentação no Ensino de Física.

Palavras-chave: Experimentação, Ensino de Física, Ensino Superior
\end{abstract}

The experimentation is without doubt a great pillar of Physics and an important way to build the teachinglearning process. However, only the experimentation, without a deep reflection of the phenomenon without to give the opportunity for students to question it and build a view of the phenomena of nature may be a pseudo-learning. In this paper, we are going to explain about the motivations, conditions and possible contributions of the experimentation in Physics Teaching.

Keywords: Experimentation, Physical Education, Higher Education

\section{INTRODUÇÃO}

É comum nos depararmos com professores de Física enfrentando grandes dificuldades em construir o conhecimento junto com seus alunos de maneira prazerosa, contextualizada e funcional. Tradicionalmente a Física é vista pelos professores como uma disciplina difícil de ser ensinada e com isso os alunos apresentam desinteresse e dificuldades de aprendizagem dos conteúdos. No entanto, a sociedade hoje se nega a aceitar um procedimento com aulas exclusivamente expositivas e exigem do professor aulas dinâmicas e criativas que despertem o interesse dos educandos.

$\mathrm{O}$ ato de experimentar, ou seja, realizar e/ou observar fenômenos da natureza, é um dos pilares da Física, e é também de fundamental importância no processo ensino-aprendizagem da Física. Esta ênfase por um ensino experimental, adicionam-se importantes contribuições da teoria da aprendizagem em busca da construção do conhecimento.

Atualmente, o ensino é visto como um objeto abstrato, longe da realidade dos alunos, o qual gera um desinteresse total pelo trabalho escolar. Os alunos preocupam-se apenas com a nota e com a promoção, os conteúdos estudados são logo esquecidos e aumentam os problemas de disciplina. Isso agrava também aos professores refletindo-se diretamente no aumento da problemática que se enfrenta no ensino superior. O raciocínio lógico não foi desenvolvido de uma maneira satisfatória, e desta forma o problema se agrava.

O presente trabalho trata-se de uma proposta, para subsidiar a procura por experimentos que despertem o interesse e a atenção ao fenômeno e à explanação do professor, para minimizar os problemas enfrentados nas universidades, por professores e alunos no processo ensinoaprendizagem de Física. 


\section{MATERIAL E MÉTODOS}

O homem é um ser pensante, e como resultado disso, possui dúvidas e questionamentos que necessitam de respostas e reflexões. Este dipolo perguntas-respostas é o que fez nossa civilização, ao longo dos séculos, avançar na compreensão da natureza e na resolução de seus problemas e questões fundamentais. Muitas das respostas se opunham ao que à época era considerado como verdade absoluta. Foi graças a grandes homens, como Galileu Galilei, Isaac Newton e Albert Einstein, que a partir de reflexões críticas, e da não aceitação do senso comum, que grandes revoluções na nossa concepção dos fenômenos naturais ocorreram.

Uma das formas de se responder a problemas propostos, que foi construída ao longo dos séculos, e sistematicamente aceito pela comunidade acadêmico-científica, é a prática e o desenvolvimento da pesquisa científica. Neste âmbito Gil [1] afirma:

"pode-se definir pesquisa como o procedimento racional e sistemático que tem como objetivo proporcionar respostas aos problemas que são propostos. A pesquisa é requerida quando não se dispõe de informações suficientes para responder ao problema, ou então quando a informação disponível se encontra em tal estado de desordem que não possa ser adequadamente relacionada ao problema".

Ainda de acordo com Gil [1]:

"a pesquisa é desenvolvida mediante o concurso dos conhecimentos disponíveis e a utilização cuidadosa de métodos, técnicas e outros procedimentos científicos. Na realidade, a pesquisa desenvolve-se ao longo de um processo que envolve inúmeras fases, desde a adequada formulação do problema até a satisfatória apresentação dos resultados".

Nossa ideia se encaixa na perspectiva e conceituação de pesquisa de Carlos Gil, na medida em que é necessário um levantamento, ordenação e reflexão acerca das práticas de instrumentação no ensino de Física.

Complementando a ideia de pesquisa, podemos considerá-la segundo Lakatos et. al. [2]:

"procedimento reflexivo sistemático, controlado e crítico, que permite descobrir novos fatos ou dados, relações ou leis, em qualquer campo do conhecimento. A pesquisa, portanto, é um procedimento formal, com método de pensamento reflexivo, que requer um tratamento científico e se constitui no caminho para conhecer a realidade ou para descobrir verdades parciais".

Retomando a conceituação de Lakatos et. al. [2], a abordagem utilizada no método deste trabalho será a qualitativa. Conforme Marques [3]:

“Abordagem qualitativa é aquela cujos dados não são passíveis de serem matematizados. É uma abordagem largamente utilizada no universo das ciências sociais e, por conseguinte da educação, quando a opção é trabalhar principalmente com representações sociais, que grosso modo podem ser entendidas como a visão de mundo. Buscar uma explicação da realidade via abordagem qualitativa corresponde compreendê-la a partir da revelação dos mapas mentais dos sujeitos-objeto da investigação. Interessa, pois, nessa abordagem apreender as percepções comuns e incomuns presentes na subjetividade das pessoas envolvidas na pesquisa, notadamente na condição de objeto-sujeito. Prestam-se como instrumentos de coleta de dados nessa abordagem a entrevista, questionários abertos, registros fotográficos, filmagens, técnicas de discussão em grupo, observação sistemática e participante e outras que o investigador poderá citar e/ou adaptar". 
Apesar de poder ser uma pesquisa do tipo quantitativa, optamos pela qualitativa, pois queremos pontuar acerca do tema de forma mais reflexiva e menos numérica. Desta forma, para fazermos esta análise qualitativa, utilizaremos como instrumento de pesquisa, o levantamento bibliográfico.

Gil [1] aponta que:

"Pesquisa bibliográfica é desenvolvida a partir de material já elaborado, constituído principalmente de livros e artigos científicos. Embora em quase todos os estudos seja exigido algum tipo de trabalho desta natureza, há pesquisas desenvolvidas exclusivamente a partir de fontes bibliográficas. Boa parte dos estudos exploratórios pode ser definida como pesquisas bibliográficas. As pesquisas sobre ideologias, bem como aquelas que se propõem à análise das diversas posições acerca de um problema, também costumam ser desenvolvidas quase exclusivamente a partir de fontes bibliográficas".

Ainda para Lakatos [2]:

"A pesquisa bibliográfica, ou de fontes secundárias, abrange toda bibliografia já tornada pública em relação ao tema de estudo, desde publicações avulsas, boletins, jornais, revistas, livros, pesquisas, monografias, teses, material cartográfico etc., até meios de comunicação orais: rádio, gravações em fita magnética e audiovisuais: filmes e televisão. Sua finalidade é colocar o pesquisador em conato direto com tudo o que foi escrito, dito ou filmado sobre determinado assunto, inclusive conferencias seguidas de debates que tenham sido transcritos, por alguma forma, quer publicadas, quer gravadas".

Desta forma, abordaremos as perspectivas teóricas de diversos autores, para justificar e fundamentar nosso trabalho. Espera-se, que sirva de auxílio aos docentes que enfrentam dificuldades em trabalhar a Física de forma dinâmica e ligada à vida dos educandos. A seguir, veremos a importância do livro didático no contexto da pesquisa e da experimentação voltado ao Ensino de Física.

\section{RESULTADOS E DISCUSSÃO}

Pesquisas têm apontado o livro didático como o principal controlador do currículo e orientador dos conteúdos e atividades a serem ministrados pelos professores.

Moreira [4] defende princípios para uma aprendizagem significativo-subversiva, onde sugere a descentralização do livro texto e uso diversificado de materiais instrucionais, tais como: documentos, artigos, obras de arte e literárias entre outros. Para este autor, o livro didático simboliza aquela autoridade de onde "emana" o conhecimento e onde professores e alunos se apoiam em demasia.

Como um recurso com espaço marcante na educação, o livro didático, alcança hoje maior abrangência, devido aos programas de distribuição do governo. Segundo Höfling [5], são programas de proporções gigantescas e dos mais amplos em termos mundiais. Este instrumento pedagógico torna-se cada vez mais objeto de estudos nos centros acadêmicos, onde se procura compreender e enriquecer as formas de avaliá-lo e usá-lo.

O livro texto apresenta-se, portanto, como um recurso importante de apoio ao processo ensinoaprendizagem dentre vários outros possíveis. Porém, adotar e utilizar apenas um, pode limitar a visão de professores e alunos quanto ao ensino de ciências, restringindo-o a uma mera repetição de conceitos e conteúdos, impossibilitando uma reflexão crítica do fazer e ensinar ciências, agravado pelas dificuldades do professor em sua prática docente: carga horária extensa, grande número de aulas e alunos e poucas oportunidades de se atualizarem, entre outras.

Segundo Rego [6]: 
"O desenvolvimento pleno do ser humano depende do aprendizado que realiza num determinado grupo cultural, a partir da interação com os outros indivíduos da sua espécie".

Nesse contexto, percebe-se a importância das trocas interpessoais e a aprendizagem interativa na constituição do conhecimento.

Em Vygotsky [7] é possível compreender a importância da significação dos conceitos, visto que, é na interação, mediada pela linguagem, que se formam os conceitos do cotidiano, que reelaborados na mente dos indivíduos irão refletir as suas vivências do meio cultural. Nesse caso, o aluno não é simples receptor, mas faz parte de um processo de construção dos conceitos que, inclusive, valoriza os conhecimentos do cotidiano, parte deles para a construção de saberes mais sistematizados. Sendo assim, saber Física passa a significar o emprego de instrumentos conceituais para dialogar com o mundo em vários níveis do seu contexto.

A leitura em Vygotsky permite a compreensão do processo do conhecimento, principalmente pela relação dialética da constituição da consciência pelos conceitos cotidianos e os conceitos que são sistematizados pela escola. A estrutura é reconstruída através da prática social dialógica (mediada pela palavra) e pedagógica (mediada pelo outro). O significado da palavra transforma-se ao longo do desenvolvimento do sujeito que, por sua vez, busca novos sentidos e novas compreensões.

No que tange ao ensino, as atividades experimentais, as chamadas aulas práticas, são frequentemente apontadas, em discussões acadêmicas, como importantes recursos didáticos das disciplinas científicas em qualquer nível de ensino. Justifica-se, assim, uma reflexão sobre a função e a importância dos experimentos no ensino de ciências, especialmente os que envolvem conhecimentos de Física.

A experimentação em si, dissociada de uma estratégia de ensino mais abrangente, não é suficiente que o aluno apenas manipule "coisas", isto seria apenas uma contribuição ao seu desenvolvimento intelectual. Por outro lado, tais contribuições não devem ser superestimadas e nem subestimada demasiadamente e sim associada a uma boa didática, antes da construção do conhecimento científico, propiciando que os alunos aprofundem seus conhecimentos em Física e estimulem a buscar soluções.

Como nem sempre os experimentos confirmam uma hipótese na forma de generalização ou lei, em muitas instituições não existem laboratórios específicos para o ensino de Física, o que aumenta as possibilidades de um experimento não atingir seus objetivos. Desta forma, cabe ao professor encontrar atividades que limitam a demonstrar aos alunos, fenômenos com a finalidade de motiválos e ilustrar sua exposição e buscar alternativas para desenvolver as habilidades e competências.

Nesse sentido, é essencial, em relação aos processos interativos e dinâmicos que caracterizam a aula experimental de ciências, a ajuda pedagógica do professor que, de forma não simétrica, faz intervenções e proposições sem as quais os alunos não elaboram. De nada adianta realizar atividades práticas em aula se as mesmas não propiciam o momento da discussão teórico prática, que transcende o conhecimento de nível fenomenológico e os saberes cotidianos do aluno, e leve a novos entendimentos e produções.

E ainda, no que se refere à falta de compreensão da função da experimentação no ensino, Maldaner [8] coloca-nos a ideia de que a experimentação, quando não se compreende a sua função no desenvolvimento científico, acaba tornando-se um item do programa de ensino e não princípio orientador da aprendizagem. Para tanto, é possível perceber a relevância atribuída às atividades experimentais e, assim, ao serem realizadas, com determinado rigor científico as mesmas possam contribuir com o processo ensino-aprendizagem.

O experimentalismo puro, sem contexto, usado simplesmente como fuga do binômio quadroexplanação, com o objetivo de somente tirar o aluno do estado passivo e inerte da sala de aula, não é eficaz e nem recomendado ao processo de educação. Acreditamos que a atividade experimental, pode e deve ter dimensões maiores e mais importantes do que estas, deve ter significados coerentes e claros para alunos e professores. Para tanto, outras formas de atividades experimentais também podem ser utilizadas, tais como: as de demonstração realizadas pelo professor ou descrição de alguma atividade experimental, em que, aluno e professor possam conhecer procedimentos e/ou equipamentos utilizados por algum cientista ou que fazem parte do mundo tecnológico em que 
vivemos Dependendo de como são propostas, estas atividades podem contribuir para esta formação mais abrangente, possibilitando o enriquecimento das relações sociais e a inter-relação entre os conceitos científicos e espontâneos, bem como o interesse dos alunos pela ciência.

Realizar um experimento sem pensar nestas questões, sem direcionar um debate, sem promover uma leitura atenta e articulada com os conceitos e o cotidiano dos alunos, poderá reduzir esta prática a mais um item curricular, que na visão dos educandos, pode ser tão chato e sem sentido quanto os conteúdos ministrados de maneira compartimentalizadas.

Compreendemos assim que a utilização dos experimentos são uma forma enriquecedora para ensinar os conceitos da Física, a instrumentação da área e a correlação desta com seu cotidiano, compreendendo-a como uma ciência de seu entorno. Ressaltamos aqui a importância da utilização de várias fontes teóricas, tornando o ensino como espaço de troca e reflexões. Os espaços também diversificados exemplificam aos alunos que o estudo da ciência acontece nos mais variados locais: em sala, em casa, nos laboratórios estruturados e não estruturados.

\section{CONCLUSÃO}

No sistema formal de ensino, quando a problematização ocorre de forma mais sistemática passase a reconhecer as limitações mais assiduamente e a buscar soluções.

Na interação com os docentes das universidades, isso também é plausível, uma vez que passaram a admitir suas dificuldades em realizar um trabalho pedagógico em Física que valorize o conhecimento cotidiano dos estudantes e a significação de conceitos. Isso é um passo importante para mudar a ação pedagógica, abandonar a postura de professor transmissor, e adotar uma prática dialógica que estabeleça conexão entre conhecimentos (cotidiano e científico) e as condições através das quais o aluno aprende.

A revisão bibliográfica vem tornando mais visível o papel da experimentação como estratégia de ensino que vincule dinamicamente a ciência com vivências do aluno. Nesse caso, extrapola a visão desconectada e distante, os meros pacotes de conteúdos a serem reproduzidos sem inserções/inter-relações efetivamente problematizadoras das formas de ver e lidar com situações, fatos e fenômenos, nas vivências de dentro e fora da escola. Em outras palavras, pretende-se valorizar a visão do conhecimento universitário como um saber mediador, dinâmico, provisório, capaz de articular o prático com o teórico, o cotidiano com o científico, e vice-versa.

\section{AGRADECIMENTOS}

Programa Institucional de Bolsas de Iniciação Científica PIBIC/CNPq. Universidade Federal do Sul e Sudeste do Pará.

\section{REFERÊNCIAS BIBLIOGRÁFICAS}

1. Gil AC. Como elaborar Projetos de Pesquisa. 3. ed. São Paulo: Atlas; 1991.

2. Lakatos EM, Marconi MA. Fundamentos de Metodologia Científica. 2. ed. São Paulo: Atlas; 1991.

3. Marques HR, Manfroi J, Castilho MA, Noal ML. Metodologia da pesquisa e do trabalho científico. 2. ed. rev. Campo Grande: UCDB, 2006.

4. Moreira MA. Aprendizaje significativo crítico. Indivisa Boletín de Estudios e Investigación, Madrid, v. 6, n. 5, p. 82-102, 2005.

5. Höfling ME. A trajetória do programa nacional do livro didático do ministério da educação no Brasil. In:

Fracalanza H e Neto JM (Org.). O livro didático de ciências no Brasil. Campinas: Editora Komedi; 2006.

6. Rego TC. Vygotsky: uma perspectiva histórico-cultural da educação. 12. ed. Petrópolis: Vozes, 2001.

7. Vygotsky L. A construção do Pensamento e da Linguagem. São Paulo: Martins Fontes; 2001.

8. Maldaner OA. A formação inicial e continuada de professores de química: professores/pesquisadores. 2. ed. Ijuí : Ed. Unijuí; 2003. 